\title{
Nontraditional Family-Related Attitudes in Japan: Macro and Micro Determinants
}

\author{
Minja Kim Choe, Larry L. Bumpass, Noriko O. Tsuya, and Ronald R. Rindfuss
}

Developed countries have undergone extensive structural changes in educational attainment, female employment, and aspects of family life. Substantial changes have also occurred in attitudes about family behaviors and gender-based aspects of employment and the workplace. While it seems obvious that micro-level attitudes, behaviors, and social interactions are linked among themselves and to macro-level changes, we do not have an adequate understanding of the mechanisms by which micro-level interactions and behavior are linked to macro-level changes and vice versa (Granovetter 1973, p. 1360). Further, for methodological reasons, establishing causal linkages among micro-level attitudes and behaviors has proven elusive. In this article we examine the case of Japan. Using crosssectional and longitudinal data from Japan for 1994, 2000, and 2009, we show that there has been substantial, but temporally uneven, attitudinal change. Both cohort replacement and period factors have been important, and change has been structured along gender lines. Further, we find that family behaviors causally affect attitudes and that interacting with individuals who have cohabited results in movement toward nontraditional attitudes. We look at a variety of attitudinal items, thereby sidestepping problems associated with putting too much weight on one or two items (see discussions in Brewster and Padavic 2000; Thornton and Young-DeMarco 2001). We focus on broad patterns across the items rather than on all the differences among them.

\section{Background}

Changing institutional contexts in developed countries during the past 40 years have included significant increases in educational attainment (especially for women) and in women's paid employment outside the home. Changes have also taken place in the structure of the labor market involving increases in jobs in the service sector, increased agricultural labor efficiency, movement of manufacturing jobs to developing economies, and a rise in contingent employment with less job security, lower pay, and fewer fringe benefits. These changes have had a profound influence on the lives of young adults, placed stress on the traditional family institution, and created conditions favorable for family change. We take these institutional changes as given and ask what mechanisms might lead to change in family values.

Substantial changes in family behavior have also occurred, including increased premarital sex, the rise of cohabitation, increased childbearing outside marriage, and a greater likelihood of divorce. Concomitant with, and inextricably linked to, institutional changes 
and changes in family behavior have been transformations in family and gender-role attitudes in many countries (Cotter, Hermsen, and Vanneman 2011; van Egmond et al. 2010; Fortin 2005; Thornton and Young-DeMarco 2001). These attitudinal changes provide an opening for further behavioral changes, with social networks and the media allowing individuals to evaluate the advantages and costs of changing family behavior (Rindfuss et al. 2004).

In the face of such institutional and familial changes, it is necessary to consider two distinct meanings of "social structure" as they relate to social relations; both are relevant to understanding macro-micro links to attitudes. The first, which has a long history in social demography, is the way in which classic social demographic variables such as education, age, sex, religion, and income create a multidimensional space. Social relations, especially those that are likely to influence attitudes and behavior, tend to occur within rather than across cells in this multidimensional space. Hence, these structural factors act as filters through which attitudes affect behaviors. Further, these structural factors themselves can affect attitudes. For example, individuals with higher levels of education are more likely to hold nontraditional family attitudes.

The second meaning of social structure arises from the social networks literature, which is concerned with interactions among individuals, households, or other social units. These interactions are generated by such relationships as kin ties, neighborhoods, the workplace, and friendships. Even with the impressive variety of today's communication systems, social relations tend to be local, and hence are nested within cities/villages, states/provinces, and countries. In recent years, social network approaches have been incorporated within social demographic research (for theoretical and methodological reviews, see Casterline 2001; Morris 2004).

Our argument ${ }^{1}$ is that change in other social institutions (e.g., education, the economy, and the polity) has created tensions in many countries affecting the norms, values, and roles associated with the traditional family institution. For example, increased educational requirements and the early apprenticeship aspects of some career ladders make traditional early (late teens and early 20s) marriage and parenthood problematic. Yet, just because there are tensions does not necessarily mean that the family institution will change, nor does it mean that all countries will follow the same path. As the tension increases between other institutions and family roles, norms, and values, the foundation is laid for alternative solutions that differ from traditional family behaviors. Societies have always had people who engaged in nontraditional family behaviors. They were typically few in number and were often the object of scrutiny and disapproval. Given changes in other institutions, more individuals might turn to nontraditional family behaviors, and observers might take a fresh look at these behaviors. For example, how are cohabiters faring? Is a child in a childcare center thriving or not? Is a mother better able to balance work and childcare roles? If the judgment is less negative or even positive, then people may change both their attitudes and their behavior. Changes in attitudes could create a feedback mechanism to changes in behavior by altering the value climate. And changes in behavior can create a feedback

\footnotetext{
${ }^{1}$ This argument is presented in more detail in Rindfuss et al. (2004).
} 
mechanism to changes in attitudes. Such change, born out of micro-level social relations, can lead to a threshold at which a macro-level realignment of the family institution occurs.

Consider American behavior and changing attitudes toward the use of childcare centers. In the 1960s, few parents used childcare centers and most believed that a preschool-age child would suffer if the mother worked. Use of childcare centers later increased. Fewer and fewer people thought that a preschool child suffered as a result. Indeed, nonworking mothers started putting their children in daycare centers because they thought it helped with child socialization. All of this happened despite a lack of scientific consensus on the effects of daycare centers on enrolled children (Bumpass 1990). We expect that people watched parents who were using childcare centers, formed opinions, and then changed their behavior and opinions accordingly. But we have no data to examine this argument for the United States and thus are left with speculation. In this article we advance such causal issues for Japan, where family changes occurred later than in the West and where data are available to address these issues.

Our arguments are compatible with those of Lutz, Skirbekk, and Testa (2006), who proposed the "low-fertility trap" hypothesis. They argued that low fertility (TFR below 1.5) for a long enough time produces a generation who grew up seeing a large fraction of adult men and women who did not become parents or who had only one child. They are socialized to think this is acceptable and they, in turn, have low fertility preferences.

The arguments we have presented to this point are about a transition in behavior and values. Inevitably, such a transition will run its course. Recent research has suggested that in several countries a leveling off has been reached in family and gender attitude changes (Brewster and Padavic 2000; Cotter, Hermsen, and Vanneman 2011; van Egmond et al. 2010), with such phrases as "the end of the gender revolution" and "a stalled revolution" in their titles. While time will tell whether these recent trends are a pause or a stall, the issue of a longlasting plateau is important because family and gender role attitudes are tied to behaviors and to macro-level values.

Family and gender role attitudes are situated within a broader set of attitudes and values, indeed within a culture. Even those who expect movement toward ideational convergence recognize that a society's cultural heritage is an important component of its trajectory of attitude change (e.g., Inglehart and Baker 2000). We now turn to a discussion of cultural, historic, and demographic factors specific to Japan that are likely to influence that country's family attitudes.

\section{Why Japan?}

Given that most of the literature on family and gender role attitudes involves Western countries, especially the United States, Japan represents an important case, one with a strong Confucian influence on the family system and an emphasis on filial piety and the patrilineal line (Aruga 1960; Taeuber 1958; Tsuya and Bumpass 2004). Japan is a homogeneous society in terms of ethnicity and language (Levey and Silver 2006), as well as relatively homogeneous and somewhat unusual regarding religion. Buddhism and Shintoism have long been part of Japanese society. Japan does not experience the competition between religious 
perspectives that is common in many Western societies; it is not problematic for a Japanese to have, for example, a Shintoist wedding and a Buddhist funeral.

Like many Western countries, Japan has experienced increases in educational attainment, urbanization, and postponement of marriage. These trends over 1994-2009 can be seen in Table 1, which gives descriptive statistics for the three cross-sectional surveys used here for respondents aged 20-49. (Descriptions of these data sets are provided below.) Unlike Western societies, Japan has a tradition, though weakening, for first-born males to reside with their parents after marriage, with the first-born male and his wife caring for his parents as necessary (Retherford, Ogawa, and Matsukura 2001). For both men and women there is also a strong tendency to live with one's own parents until marriage. For both sexes, the increasing postponement of marriage has led to an increase in time residing with parents. There has also been some increase in cohabitation, but the levels remain low relative to Western Europe and North America (Raymo 2003; Tsuya 2009).

Relative to other developed countries, Japan is an outlier on gender role attitudes (e.g. Figure 3 in Inglehart, Norris, and Welzel 2002), tending to hold traditional views. One also finds discrimination against women in the labor market, with women in paid employment encouraged to quit upon marriage or the first birth, as well as work environments that are often unfriendly to women (Brinton 2001; Yu 2005). Japan has one of the highest wage gaps between men and women among OECD countries (Fortin 2005), largely as a result of a high proportion of women in temporary employment, and it ranks low on laws protecting working women against discrimination (Chang 2000). Japanese wives shoulder almost complete responsibility for raising children, with husbands contributing little (Hirao 2001). Affordable, good-quality childcare services are lacking, especially in urban areas (Lee and Fujita 2011). Further, the demands of the after-school private, supplementary education system (juku) place heavy demands on mothers' time, including getting their children ready for juku and supervising take-home assignments (Tsuya and Choe 2004; Ogawa et al. 2009). Given these structural factors, it is very difficult for women to combine mother and worker roles in Japan, especially for those with regular, fulltime jobs, which entail long work hours and an inflexible work schedule (Lee and Fujita 2011).

With the exception of a few years, the Japanese economy has been stagnant since the stock and housing market collapsed in the early 1990s (Cotis 2003; Yoshitomi 2004; Yu 2012). In an attempt to increase their competitiveness and profitability, employers have begun to abandon the lifetime employment model, traditionally a distinguishing feature of the Japanese labor market (e.g. Brinton 2011; Roberts 2007; Genda 2005). This has led to an increase in the proportion of employees working in temporary positions such as keiyaku (those hired under a fixed-term contract with limited provision of social insurance and other fringe benefits) or haken (contract work whereby an agency sends workers to a corporation for a specified period) (Igarashi 2009; Somusho Tokeikyoku 2006). As a result, many young people are marginalized in contingent jobs, which recent research suggests has more detrimental long-term effects on occupational status than being unemployed (Yu 2012). A rise in the percentage in these nonregular jobs is evident starting around 2000 for persons aged 25-34 (Statistics Japan 2012). 
Finally, Japan's tax and pension systems discourage wives' extensive employment. If the spouse earning less in a marriage (usually the wife) earns more than a certain threshold, the other spouse's tax liability increases (in some cases yen for yen), and consequently the lower earner becomes liable to contribute more to the national pension system and pay for her or his own health insurance (Akabayashi 2006; Yu 2002). Further, the tax and pension rules affect hours worked by wives employed part-time (Akabayashi 2006), and Yu's (2002) qualitative data make it clear that Japanese wives are well aware of these circumstances. ${ }^{2}$

\section{Causal issues}

Empirically identifying factors that influence family and gender role attitudes, and their trends, has proven difficult at both the macro and micro levels. Consider the macro level first. Specific period factors, such as the election of a conservative ruling coalition in Australia in 1996 (van Egmond et al. 2010) or shifts in Americans' positions regarding civil liberties, civil rights, and sexual tolerance (Brooks and Bolzendahl 2004), have an associational relationship with a shift (or lack thereof) in family and gender role attitudes. But to prove a causal effect requires an effective way to rule out or control for other changes in the period that might also affect family and gender role attitudes. This task is usually difficult or impossible.

An exception at the macro level is research in social demography that examines cohort replacement effects compared to period effects (e.g. Brewster and Padavic 2000; Brooks and Bolzendahl 2004; Cotter, Hermsen, and Vanneman 2011; Davis 1992; Lee and Fujita 2011; Mason and Lu 1988; Yamaguchi 2000). In this literature, "period effects" do not refer to specific period factors, but rather indicate that an unidentified factor in a given time period led to a shift in attitudes. Similarly, finding a cohort replacement effect does not specify what was different about the cohorts entering compared to those leaving, but only that the two cohorts differ. At this level of specificity, period and cohort are clearly exogenous, and straightforward techniques for estimating period effects versus cohort replacement have been developed (Firebaugh 1989). In this article we examine the extent to which both period and cohort factors are operating, and find differences comparing the periods 1994-2000 and 2000-09. We speculate on the period and cohort factors that were important but, like others, we cannot demonstrate the particular causal mechanisms.

At the micro level, we first consider changes in marital and parental status. It is frequently acknowledged that such variables are likely to be endogenous (Brooks and Bolzendahl 2004; Cotter, Hermsen, and Vanneman 2011; van Egmond et al. 2010). Further, there are probably unmeasured variables that affect marriage and childbearing behaviors and

\footnotetext{
${ }^{2}$ The following quote from one of Yu's informants makes it clear that at least some wives are well aware of the tax situation. This is from a woman, age 50, who worked in a post office part-time:

I wish I could work longer hours. My husband was sent to a branch in another area and my son moved to school. Now I live by myself and have a lot of time to work. But, see, my husband gets 1,500,000 yen annually as the family subsidy. If my income is under 900,000 yen a year-I think it is 900,000 yen now-I don't need to pay tax and my husband would receive the subsidy because I don't have any taxable income. So if I earn 900,000 yen a year, we get 2,400,000 yen in total. But if I work more and earn 1,000,000 yen annually, he will get no subsidy and I need to pay tax, too. I will finally get much less. In order to make it worth it, I will need to work twice the amount of time and earn more than 2,400,000 yen a year, after tax. But it's not easy to find a good job like that. (Yu 2002, pp. 516-517)
} 
attitudes, again suggesting endogeneity. Commitment to one's career is a possibility. In short, many characteristics of individuals and couples are probably endogeneous, and simply including them in an equation as exogenous variables can lead to biased results. While researchers recognize this endogeneity issue, it has been difficult to address it in an econometrically satisfactory way. In analyses below we use a rich set of community variables and an instrumental variables approach to control for endogeneity. The technical details are provided in an appendix available from the authors on request. ${ }^{3}$

Also at the micro level, it has been difficult to address social network influences on attitudes. First, feedbacks in the system make it difficult to ascertain what is influencing what. Second, people cannot be randomly assigned to families, friendship groups, or neighborhoods. Rather, with the exception of certain relatives, people choose their friends, co-workers, and neighbors, and this makes it difficult to move from association to causality. The fact that people choose the members of their social network creates what Manski (1993) has called the "reflection problem" (see also Duncan, Boisjoly, and Harris 2001; Moffitt 2001; Mouw 2006). For example, if a person, ego, picks a friend who has the same attitudes as ego, then there would be a perfect correlation between ego's and friend's attitudes, but no underlying causal relationship. Again, in the analyses below, we use various community variables and an instrumental variables approach to address this issue.

\section{Data and measures}

This study uses replicated cross-sectional data from three nationally representative surveys: the 1994 National Survey of Work and Family Life (NSWFL) and the 2000 and 2009 National Survey on Family and Economic Conditions (NSFEC). ${ }^{4}$ Field work for all three surveys was carried out by the same data collection organization employing comparable methods. The 1994 NSWFL sampled Japanese men and women aged 20-59. Both the 2000 and 2009 NSFEC sampled Japanese men and women aged 20-49. The 2000 and 2009 crosssectional surveys oversampled persons aged 20-39, and weights are used to account for this oversampling and for differential response rates by age, sex, and size of place of residence. ${ }^{5}$ Because the 2000 and 2009 surveys had an upper age limit of 49, we restrict analysis of the 1994 data to those aged 20-49. The 2000 NSFEC respondents were also followed up in 2009 , using a questionnaire identical to the one used for the 2009 cross-sectional survey. We use the longitudinal information in the instrumental variables models; an appendix available from the authors provides details.

In each survey, respondents were asked to rate their level of agreement with various statements about family behaviors and gender roles. We examine 16 attitude items classified into three groups. The first group, centrality of marriage and childbearing, was measured using six questions shown in the top panel of Table 2, which lists the item and indicates the response considered nontraditional, the surveys in which the item was included, and the

\footnotetext{
${ }^{3}$ The appendix and tables mentioned below are available on request (mchoe@ hawaii.edu).

${ }_{5}^{4}$ Details of 1994 NSWFL are found in Tsuya and Bumpass (2004) and details of 2000 NSFEC are found in Rindfuss et al. (2004).

${ }^{5}$ All three surveys were two-stage samples, with the first stage sampling geographic primary sampling units (PSUs). In the second stage, Japan's basic residence registration (jumin kihon daicho) was used. This registration covers the entire population and contains each individual's name, age, sex, and current address at the time the sample is drawn. Thus, even for nonrespondents, we know their age, sex, and size of place of residence and can incorporate these data into the weights.
} 
abbreviation used in subsequent tables and figures. All of these questions on the centrality of marriage and childbearing have an "ought" connotation in the traditional Japanese family realm, where men and women are expected to marry and have children soon thereafter.

The second group, acceptability of nontraditional family behavior, was measured by the four statements in the middle panel of Table 2. These four items deal with behavioral trends found in many countries that involve applying aspects of traditional marriage to nevermarried individuals. The first three ask about unmarried individuals having sexual relations, living with a member of the opposite sex, and giving birth outside of marriage-all behaviors traditionally reserved for married individuals. The fourth item contrasts parental responsibility to children with the individual desire to escape an unhappy or unfulfilling marriage.

The third group, attitudes about wife's employment and the family, was measured by six items. These questions deal with the gender-based intersection of family and work. In the traditional Japanese context, women were expected to exit the labor force upon marriage (or at the latest after becoming a mother), and men were to be the family's breadwinner (Atoh 2001; Lee, Tufiş, and Alwin 2010; Retherford, Ogawa, and Sakamoto 1996). These expectations were institutionalized in the workplace, especially within large firms ( $\mathrm{Yu}$ 2002). After marriage, wives were supposed to devote themselves full-time to caring for the household, raising children, and, if married to a first-born son, to care for her husband's parents.

For each of the 16 questions, respondents were asked to choose from five response categories consisting of (1) strongly agree, (2) agree, (3) neutral, (4) disagree, and (5) strongly disagree. In the following analyses, items were reverse-coded as needed, so that for all items a higher score represents a less-traditional position. For some analyses, the two "agree" responses (strongly agree and agree) are combined into a single category, and similarly the two "disagree" responses are combined. In the surveys on which this study is based, as is typical in Japanese surveys in general (Shishido, Iwai, and Yasuda 2009), a large proportion (by international standards) of respondents chose the middle (neutral) category. To check whether this is due to a "response set," with large numbers of respondents automatically picking the middle category on all items, we looked at patterns of response overlap across items. There is a low level of response overlap (that is, different respondents chose the middle category as their response to different items), suggesting that we are not facing a response-set problem.

\section{Trends in attitudes}

The proportion of men and women giving a nontraditional response for each of the 16 attitude items for each time period is shown in Figure 1, with separate panels for the three clusters of items. ${ }^{6}$ For the four centrality of marriage and childbearing items included in the three surveys (which ask about "a full and satisfying life" without children/marriage for men and for women), the percentages reporting nontraditional views were low in 1994, ranging

\footnotetext{
${ }^{6}$ Detailed tables for these distributions and others later in the article are available on request.
} 
between 18 and 26 percent (top panel). From 1994 to 2000, however, the percentages increased markedly for all four items. These increases correspond closely to behavioral changes that were also occurring, such as increasing proportions never-married and remaining childless (National Institute of Population and Social Security Research 2013, pp. 70, 109; Retherford, Ogawa, and Matsukura 2001). In contrast, there is relatively little change from 2000 to 2009. Indeed, the percent giving a nontraditional response to the item about a woman having a full and satisfying life without marrying actually declined to the 1994 level.

In all three survey years, marriage is seen as more essential for men than for women (top panel, Figure 1). This probably reflects, at least in part, Japanese men's dependence on their wives to provide a variety of support, including performing basic household tasks (Tsuya et al. 2005, 2012). It is notable that the proportions endorsing the nontraditional view regarding parenthood-those agreeing that a full and satisfying life can be enjoyed without childrenare higher than those endorsing the nontraditional view of marriage. For some, then, even if marriage is viewed as necessary for a full and satisfying life, parenthood may not be. Given the extended period of very low fertility in Japan (the TFR has been 1.5 per woman or below since the early 1990s), the fact that over one-third agree that men and women can have a full life without children is consistent with the hypothesized low-fertility trap.

Two nontraditional family behavior items, one concerning the sexual behavior of unmarried women and the other concerning parental divorce, were included in all three surveys, and two additional items, one about cohabitation and another about nonmarital childbearing, were added in 2000 and 2009 (middle panel of Figure 1). According to traditional Japanese values, it was unacceptable for an unmarried woman to cohabit with a partner, have sex, or bear children before marriage, and divorce was regarded unfavorably because marriage was considered a lifelong relationship (Bumpass and Choe 2004). Three of the nontraditional family behavior items underwent relatively little change over time, and we discuss them first. Having children while unmarried remains extremely rare in Japan: only about 2 percent of all births are to unmarried women (National Institute of Population and Social Security Research 2013, p. 67). Not surprisingly, attitudes toward an unmarried woman having a child are more traditional, with only about 20 percent agreeing that this is acceptable, and there has been little change since 2000 .

Unlike nonmarital births, divorce has become quite common and is at levels that are about at the middle of rates experienced in Europe (Raymo, Iwasawa, and Bumpass 2004, Raymo, Iwasawa, and Bumpass 2005). Nonetheless, our data show low approval of divorce for couples with children, and even a decline in approval between 2000 and 2009. How do we reconcile the attitudes examined here with this behavioral change? One possibility is that the difference between attitudes and behavior (expected lifetime experience of divorce) is due to the specification "for the sake of children." A question on divorce regarding childless couples and couples with adult children might show a trend toward greater support for divorce as an option. Cohabitation is also becoming more common in Japan (Raymo 2003; Tsuya 2009), yet approval for it changed very little since 2000. Thus, three of the four nontraditional family behavior items show evidence of a leveling off in attitude changes between 2000 and 2009. 
Agreement that it is acceptable for an unmarried woman to have sexual relations is a clear exception to this leveling off. There was a steady increase in approval of this nontraditional behavior in both time periods, and this was the largest change among the nine attitude items included in all three surveys. In 1994, 29 percent of respondents aged 20-49 agreed that it was acceptable, and the same proportion disagreed. By 2009, the proportion agreeing increased to well over one half and only 7 percent disagreed. This change in attitudes toward nonmarital sex may be related to the continued increase in age at marriage, the rise in cohabitation, and recognition that the double-standard is no longer appropriate.

The final set of attitudinal items relate to women's employment and the family (bottom panel of Figure 1). With respect to levels, the highest proportion showing a nontraditional attitude is in response to "a working mother can establish just as warm and secure a relationship with her children as a mother who does not work," and this undoubtedly reflects widespread experience with mothers working. For the other items, there is still considerable tolerance for sex discrimination in the workplace, in addition to a high level of concern that preschool children suffer if their mother works. On this latter point, one should note the cognitive discrepancy between the low level of disagreement that children suffer and the fact that almost half of the mothers of preschool children were employed in 2009 (Tsuya et al. 2012).

The trend patterns for the items on women's employment are similar to those for the other attitude items. For two of the three women's employment items included in all three surveys, there is an increase in nontraditional responses in the 1990s, followed by a leveling off or slight increase in nontraditional responses after 2000. Two of the other three items available only for 2000 and 2009 show very little change during that decade, and the third shows movement toward the traditional position. The exception is the continued increase in nontraditional responses on the "children suffer" attitude noted above, though at a low level. This increase may be linked to a substantial increase in the employment of mothers with very young children (Tsuya et al. 2012).

\section{Cohort and period changes}

What might account for the trend toward less-traditional attitudes followed by a leveling off? Recall that the three surveys were based on nationally representative samples using similar procedures, and the analyses were limited to the same age range. Under these conditions, broadly speaking, the attitude differences could be attributable to two factors. The first is cohort replacement. Attitudes among older men and women are likely to be more traditional than the attitudes among more recent cohorts. Table 3 shows the birth cohorts included in the three surveys and their ages at each. Consider attitude changes between 1994 and 2000. The 1994 survey includes birth cohorts 1945-1974. In the 2000 survey, the six earliest cohorts in the 1994 survey are excluded and six more recent cohorts (1975-1980) are included. The cohort effect measures the component of change between 1994 and 2000 attributable to the inclusion of different birth cohorts. The logic extends similarly to the 2000-09 comparison. 
The second source of attitude change is change within cohorts. For example, men and women born between 1960 and 1974 were included in both the 1994 and 2000 surveys. Their ages were 20-34 in 1994 and 26-40 in 2000. The period effect measures the component of change attributable to changes in the attitudes of cohorts included in both surveys. An attitude for birth cohorts included in both surveys may change because the attitude changes with age, because of changes in the social, economic, and other conditions of society, or both. Again, the logic extends to the 2000-09 comparison.

To identify cohort and period effects, we estimated net effects from logistic regression models similar to Firebaugh's (1989) linear decomposition method for each of the nine attitude items included in all three surveys. The dependent variable in each logistic model is whether the response to a particular attitude was nontraditional. As explanatory variables, we include (1) year of survey, (2) birth cohorts, (3) sex, (4) an interaction term between survey year and sex, and (5) an interaction term between birth cohort and sex. This method is similar to that of Firebaugh except that we use a binary dependent variable and logistic regression instead of an interval-level measure dependent variable and OLS regression. The results are summarized in Table 4, showing the signs of the statistically significant $(\mathrm{p}<$ 0.05 ) coefficients, and we note that the results are similar if we examine men and women separately.

Consider period effects first. Attitudes in 2000 were less traditional than attitudes in 1994, and for each of the nine items examined positive period effects were statistically significant. In contrast, period effects between 2000 and 2009 were not statistically significant for many items, and, for three attitude items, the net period change was actually toward being more traditional. For only two items (acceptable for an unmarried woman to have sex and a working mother can establish just as warm and secure a relationship with her children as a mother who does not work) is there a significant period effect toward less-traditional attitudes. Apart from these two exceptions, the results for period change reinforce the notion that a leveling off in the trend toward nontraditional attitudes occurred since 2000. Although there is evidence that such leveling off also occurred in some Western countries (Cotter, Hermsen, and Vanneman 2011; Thornton and Young-DeMarco 2001; van Egmond et al. 2010), one must note that family and gender role attitudes in Japan are more traditional than in Western countries. We return to this topic at the end of the article.

Turning to net cohort effects, the pattern varies by item, but, in general, more recent cohorts hold less-traditional attitudes than earlier cohorts. For two items there is a positive net cohort effect for each of the four cohort comparisons, and they illustrate one aspect of the genderbased nature of family attitude change. One, "it is acceptable for an unmarried woman to have sex," also has positive net period effects in both periods, indicative of pervasive period and cohort factors leading to higher approval of sexual behavior for unmarried women. The other item with a positive net cohort effect for each of the four cohort comparisons, "a man can have a full and satisfying life without marrying," is of interest in that we do not see such pervasive cohort effects for the corresponding item for women. 


\section{Differences by sex}

Gender divisions in Japanese society are strong, and 12 of the 16 attitude items examined here are sex specific (as in "a man/woman can have a full..."). We now turn to differences by sex. It is common in developed countries for women to be more likely than men to report nontraditional views (Brewster and Padavic 2000; Brooks and Bolzendahl 2004; Cotter, Hermsen, and Vanneman 2011; Fortin 2005; van Egmond et al. 2010), and we find this for Japan. Figure 2 shows, for each of the 16 attitude items in 2009, the percentage of women holding a nontraditional attitude minus the percentage of men with a nontraditional attitude. Females are less traditional than males on all but one item, with the differences ranging from 2 percentage points for the cohabitation question to a high of about 20 percentage points for the items on women's employment outside the home. In the context of a discriminatory labor market, it is perhaps not surprising that, by a wide margin, the largest sex differences involve these two items: women should work only if the family needs the extra income, and men should get priority in hiring when jobs are scarce. The only item about which men are more likely to hold nontraditional views is "a man can have a full and satisfying life without marrying," but 2 percentage points is so small as to constitute essentially no difference.

Figure 3 shows the trend from 1994 to 2009 in the sex difference in the proportion of nontraditional responses for each of the 16 items. While there are exceptions, the general pattern is an increase in the difference by sex over time, with women moving faster toward nontraditional attitudes than men. Given the patriarchal nature of the family institution in Japan (Tsuya and Bumpass 2004), this pattern of increasing sex differences should not be surprising.

The female-male differences tended to increase the least on items related to the wife's employment and the family group. This is surprising given the discrimination that Japanese women experience in the workplace and the increasing number of Japanese women in the labor force. On the other hand, the growing precariousness of employment in Japan and the long period of economic stagnation may be exerting pressure on women to abandon liberal attitudes toward women's employment and the family.

\section{Attitude determinants}

So far we have examined structural changes in Japan's economy along with the postponement of marriage and parenthood and the rise in cohabitation. We have shown that family and gender role attitudes moved toward nontraditional positions in the 1990s and then were mostly unchanged during the 2000s. Period factors were pervasive in the 1990s but had limited influence in the 2000s. Cohort replacement tended to lead to nontraditional attitudes, but primarily for two items regarding sex among unmarried women and working mothers' relationship with their children. Women are less traditional, and the difference by sex has widened. We now turn to the link between changes in family behavior and changes in attitudes. To what extent has the increase in age at marriage and at parenthood, change in coresidence with parents, and the increase in cohabitation altered attitudes at the individual level and by inference at the macro level? 
In examining the effects of variables such as marital status or knowing someone who has cohabited, we recognize that unobserved variables might influence attitudes and be correlated with some of our explanatory variables. For example, a person prone to risktaking might be both more likely to hold nontraditional family/gender role attitudes and more likely to stay never-married. If we do not control for such unmeasured variables, our estimation of the effect of being never-married or post-married (separated, divorced, or widowed) could be biased. In addition, attitudes might affect a person's decision about getting married or living with one's parents, and ignoring this potential reverse causality could also result in biased coefficients. To overcome these problems, we use an instrumental variables approach, estimating two-stage least square models for the pooled observations of the 2000-09 panel survey and the 2009 cross-sectional survey. ${ }^{7}$ Details of the estimation procedure, including a test of the endogeneity assumption we use, are described in an appendix available on request, and here we provide only an overview.

We estimate models for 16 attitudinal variables separately for men and women. Each dependent variable is an integer variable ranging from 1 (most traditional) to 5 (least traditional). We consider marital status and parenthood status (never-married, married without children, married with children, and post-married), coresidence with parents, and whether the respondent knows someone who cohabited to be potentially endogenous. This last variable, which measures the influence of social networks, requires some explanation. In addition to the background characteristics and one's own behavior, the nontraditional behaviors of others are likely to affect an individual's attitudes. There is an association between family attitudes and whether one knows someone who has engaged in certain nontraditional behaviors (Rindfuss et al. 2004). Knowing someone who has cohabited has a consistently strong association with attitudes related to marriage, childbearing, sexual behavior, and gender roles, suggesting that knowing cohabiters is a crucial factor in family attitudinal change.

We also control for the following background variables: respondent's education (senior high school or less, junior college or equivalent, and four-year college or higher), rural residence, rural childhood residence, whether the respondent's mother had more than a senior high school education, whether the respondent's father had more than a senior high school education, and whether the respondent is a first-born child. These background variables are assumed to be exogenous. Since the distribution of these variables has been changing over time (Table 1), understanding their effects on attitudes is important to understanding the changes in family and gender role attitudes in Japan. In addition, we included age (five-year age groups), year of survey, and type of survey (cross-section or panel) as control variables.

After estimating the two-stage least squares model for each of the 16 attitude items for men and women separately, we tested the endogeneity assumption. It is possible that there is no reverse causality and that unobserved variables that affect attitudes are not correlated with the independent variables in the model. For our final models, we use the two-stage least

\footnotetext{
${ }^{7}$ Our procedure requires knowing the residence history of respondents, which is not available for the 1994 cross-section. Hence we do not use the 1994 data for this part of the analysis.
} 
squares models if there is evidence of endogeneity, and ordinary least squares models if there is no such evidence.

The endogeneity tests reveal an interesting substantive pattern by sex. Table 5 indicates that, for men, only 4 attitudinal items out of the 16 examined showed no evidence of endogeneity. In contrast, for women, 11 of the 16 items showed no such evidence. In other words, for men there are unmeasured variables that affect three-quarters of the attitudinal variables and are correlated with the observed independent variables, but for women the opposite is the case. Put differently, for women there tends not to be a set of unmeasured variables that affects: a) their family behaviors or their knowing cohabiters, and b) their family/gender role attitudes. This reinforces the differences by sex discussed above and could suggest that women are aware of and have given more thought than men to family values, conflicts with work, and the meaning of the roles of spouse and parent. Given that women experience pronounced incompatibilities between their parental and work roles, as well as discrimination in the workplace, this pattern should have been anticipated.

Table 6 summarizes the effects of family behaviors and social networks on the 16 attitudinal variables. We focus on broad patterns, especially the substantial differences by sex. Consider first the three ever-married categories relative to never-married, recalling from Table 1 that the numbers married without children and post-married are, though increasing, still relatively small. Among men, being married but childless leads to less-traditional attitudes for 11 of the 16 items; for women this is the case for seven. In Japan, being married but childless is an unusual status given that traditionally the purpose of marriage was to have children and individuals who do not want to have children postpone or forgo marriage (Bumpass et al. 2009). For some, being childless is a transitional state: 22 percent of the married childless women and 30 percent of the men have been married for less than two years. Presumably most will eventually have children. Yet, half have been married for five years or more, which may be related to fecundity or to preferences to delay having (or not to have) children. Whatever the reason for being in this nontraditional state, being in it is clearly pushing men, and to a lesser extent women, toward nontraditional attitudes. In contrast, most of the coefficients for being married with children compared to being nevermarried are not significant. For women, when they are significant, they move women toward more-traditional attitudes, likely reflecting the still highly traditional nature of the mother role in Japan.

The contrast between the effect of being post-married versus never-married and the effect of living with parents versus not is instructive from a gender perspective. For being postmarried, not a single male coefficient is significant, but several female ones are, especially those dealing with nontraditional family behaviors and wife's employment. For coresiding with one's parents, the gender differences are reversed: not a single female coefficient is significant, but several male ones are, especially those dealing with nontraditional family behaviors and wife's employment. That being separated or divorced might move women toward nontraditional attitudes is not surprising. Many of them have children and somehow they are coping, perhaps thriving. But it is surprising that men living with their parents, controlling for marital and parental status, should move toward nontraditional attitudes. 
The final two columns in Table 6 show the effects of knowing someone who has cohabited. Consistent with the associational relationships found in the 2000 cross-sectional data (Rindfuss et al. 2004), knowing someone who cohabited leads to having less-traditional attitudes, and this is especially the case for women, for whom 14 of the 16 coefficients are significant. While cohabitation has been increasing in Japan, the levels are still below those found in many Western countries. These results suggest that as cohabitation becomes more common, and as people remain in touch with cohabiters and do not have a negative reaction to such an arrangement, family and gender role attitudes will become less traditional.

The results for background variables are shown in Table 7. As has been the case in other countries (Cotter, Hermsen, and Vanneman 2011; Thornton and Young-DeMarco 2001; van Egmond et al. 2010), men and women with higher education, especially a college degree, are more likely to hold nontraditional family attitudes. This is especially the case for the variables related to wife's employment. As more Japanese obtain higher education, one would expect both men and women to recognize that women would prefer to hold interesting, well-paid jobs. Such orientations may also lie behind the fact that all four family-orientations variables that concern having children are also statistically significant and positive for women with a college education.

The effects of parents' education vary considerably by sex of respondent. (It is important to note that these are "direct" effects net of the respondent's own education, i.e. parents' education may also affect their children's attitudes indirectly through the influence of parental education on their children's educational attainment.) Father's education has little impact on the family attitudes of either men or women. This is consistent with the image of respondents' fathers' generation of "salarymen" who worked long hours, frequently socializing with co-workers after hours and spending little time with their children (Vogel 1971). Mothers with higher education, on the other hand, have relatively little impact on their daughters' attitudes, and the two significant coefficients point toward traditional attitudes. Mother's education has a more pervasive effect on their sons, however, leading to less-traditional attitudes-especially attitudes toward wife's employment and the family. It is likely that mothers with higher education have less-traditional views on gender roles, even when they were not able to behave accordingly. Sons of these women are more likely to realize the importance of nontraditional gender roles. At the same time, mothers with a high level of education may have discouraged their daughters from aspiring to nontraditional gender roles and encouraged traditional behavior for them so that they would be able to assume traditional female roles. One should recall that, by definition, the parents of our sample population are drawn from an earlier generation that was considerably more traditional.

Rural residence, whether current or origin residence, tends to lead to more-traditional attitudes, and this is especially the case for women. Thus, as Japan continues to urbanize, this force for traditionalism should continue to weaken. Somewhat surprisingly, being firstborn has almost no impact on family and gender role attitudes. 


\section{Summary and discussion}

Attitudes toward many aspects of family life in Japan shifted away from traditional values during 1994-2000 and then remained unchanged in 2000-09. There are large differences by sex, with women being less traditional. Recent cohorts are less traditional than the ones they replace. We found consistent period effects in the earlier period, but not more recently. We also found causal evidence that getting married, becoming a parent, divorcing, coresiding with parents, and knowing someone who has cohabited influence one's own family and gender role attitudes, mostly in the direction of holding less-traditional attitudes.

The attitudinal items we examined deal with core issues in contemporary Japan: balancing work and family roles, reducing discrimination against women in the labor market, challenging the unequal domestic burdens of men and women, addressing the double standard of nonmarital sexual behavior, and maintaining the ability of children to grow up in a two-parent family. These issues have far-ranging implications for major institutions within Japan, including the economy, family, education system, welfare system, and the maintenance of the Japanese population. These issues and their consequences are routinely discussed in conversation, in the media, and among policymakers. Indeed, the issues are at the heart of any country's value system. In conclusion we discuss two topics: 1) the interrelationship between Japanese policies and these family/gender attitudes and 2) the seeming contradiction between the recent leveling off in attitudinal change and causal forces leading to further attitudinal change in the nontraditional direction.

\section{Policy}

Policies and a country's value structure are typically closely related, especially in a democracy where policymakers are answerable to the electorate. Given the ambivalence found in attitudes toward family and gender role attitudes, as indicated by more-traditional views in Japan than in other high-income countries as well as the recent absence of further changes, it is worth noting that some of the same ambivalence is also found in Japan's family and gender policies. For example, the provision of reasonably priced, high-quality childcare reduces the incompatibility between the mother and worker roles, decreasing the need for women to choose between the two. Beginning with the Angel Plan in 1994 and continuing with the 2013 Plan to Accelerate the Reduction of Preschool Children on Waiting Lists (Taiki Jido Kaisho Kasokuka Puran), Japanese policymakers have recognized the need to increase the availability of childcare services (Naikakufu 2012). Yet the ultimate responsibility for providing such services has been placed on municipalities, and the central government does not provide the necessary funds for increasing childcare availability. On the other hand, the numbers on waitlists for childcare have increased, especially in urban areas (Kosei-rodo-sho 2013d), despite the fact that municipalities make it appear that the number of families seeking childcare services is smaller than the actual figures. ${ }^{8}$ Further, there is no tangible penalty to municipalities if they have a long waiting list.

\footnotetext{
${ }^{8}$ As one example, municipalities can exclude from their waitlist children whose parents are on parental leave, despite the fact that without childcare it is difficult if not impossible to return to work.
} 
The insufficient provision of childcare services is exacerbated by the fact that employees are expected to work long hours (see Tsuya et al. 2012), especially if they have a regular job with benefits and advancement opportunities. The mean hours worked per week by Japanese husbands aged 20-49 is around 50, and the same is expected of women with regular jobs. Policymakers have urged companies to reduce the length of the work week, but doing so is left to employers and they seem to have shown little inclination so far. In short, there is a desire among policymakers to increase childcare services and reduce the incompatibility between the role of mother and worker, but they often lack the will necessary to ensures that these changes occur.

A similar situation can be found with respect to parental leave. Japan first enacted the Maternity and Childcare Leave Law (Ikuji Kyugyo Ho) in 1992 and revised it in 1995, 2005, 2007, and 2009 (Kosei-rodo-sho 2010, 2013a), with 12-month compensation currently at 50 percent. To be eligible for leave, the parent (with leave typically taken by the mother) has to be covered by the national employment insurance scheme and to have worked at least 12 months during the previous two years (Kosei-rodo-sho 2013b). All employers are expected, under the law, to adopt a parental leave policy, but there are no penalties if they do not. While compliance has increased, 28 percent of all employers in 2012 still did not have rules regarding parental leave (Kosei-rodo-sho 2013c). Even if a company has a formal policy, there is likely to be informal pressure from supervisors and co-workers for a mother to relinquish her job instead of taking parental leave (Yu 2002).

This seeming ambivalence in Japan's family policy is consistent with the trends in attitudes seen above. Japan has a history of being strongly patriarchal with a male breadwinner system (Taeuber 1958; Tsuya and Bumpass 2004). Many factors conflict with these values and institutional arrangements, but the lack of more recent changes in attitudes and the absence of enforcement provisions in family/gender policies suggest that there is considerable resistance to adopting new values.

\section{Looking forward}

Our results do not provide clear-cut guidance about the future of family and gender role attitudes and the underlying value structure in Japan. The leveling off in attitudinal changes since 2000 suggests limited change. Our multivariate results, coupled with recent behavioral trends, suggest movement toward less-traditional attitudes. As we note briefly below, the forces involved are complex, feedbacks are involved, there are clear differences on specific topics under the family/gender umbrella, and period factors represent a "black box." Despite this uncertainty, our analyses lead us to suggest that further departure from the traditional value structure is likely.

Consider the black box first. The tool in social demographers' toolbox that permits examination of period and cohort effects does not identify the specific factors influencing attitudes. Rather it shows whether period effects are present and, if so, whether they are moving toward more- or less-traditional attitudes. During the 1990s period factors were pushing toward less-traditional attitudes across the entire range of family and gender role attitudes. So we know there has been a significant change in the recent past. But since 2000, there were no period effects on almost half of the attitudes, and when there was a significant 
period effect, it more often led to more-traditional than to less-traditional ones.

Undoubtedly, the leveling off in family and gender role attitudes was strongly influenced by the diminution of period effects. But because the specific mix of changes in period factors is unknown, the implications for future trends are similarly unknown.

Our results examining the causal effects of marriage, childbearing, coresiding with parents, and knowing someone who has cohabited are less equivocal and point toward further movement away from traditional attitudes. Cohabitation provides the clearest and strongest signal. Cohabitation has been increasing in Japan, and knowing someone who has cohabited has positive effects on holding less-traditional attitudes among both men and women. Note that this also likely constitutes a positive feedback loop: those with less-traditional attitudes are more likely to cohabit, which means that more people will know cohabiters. Similarly, married women with children have more-traditional attitudes than never-married women, and since the proportion of women who are never married has been rapidly and steadily increasing, there likely is an increase in less-traditional attitudes. Indeed, this feedback is probably a major component of the cohort effects and helps explain why women hold lesstraditional attitudes than men. And since an increase in the pool of never-married women permits increased cohabitation, there may be a positive feedback loop. As for men, coresiding with parents leads to less-traditional attitudes, but since there has not been any appreciable change in the proportion of men living with parents (see Table 1), the coresidence effect is unlikely to influence future attitude trends unless the proportion living with parents increases significantly.

The effects and feedbacks just described relate to the challenge from Granovetter (1973) in our opening paragraph: how are micro-level interactions and behavior linked to macro-level change? We have shown that marriage, childbearing, and coresidence with own parents affect ones' attitudes, as does the cohabiting behavior of one's relatives, friends, and coworkers. Hence, by inference, as more individuals change their attitudes and underlying values, the macro-level structure of attitudes and values also changes. Such attitudinal changes are likely to be reflected in the media, in images in literature and movies, and in utterances of politicians and other leaders, reinforcing macro-level changes.

Also suggesting further departure from traditional attitudes is that women with a college education, urban residence, urban origin, and a mother with higher education have lesstraditional attitudes. The proportion in all four of these categories has been increasing, and the expectation is that there will be further increases in the future.

Finally, changes in Japan's attitudes and behaviors have not followed a single path as some who have watched change in Europe would have predicted. The traditional value structure in Japan dictated that young men and women should marry in their mid-to-late-20s (Brinton 1992; Taeuber 1958, pp. 210-213) and then have a child as soon as possible. Children were to be born only within marriage. The proportion of Japanese with attitudes approving nonmarital childbearing is low. Nor has behavior changed: the proportion of nonmarital births has remained at about 2 percent of all births (National Institute of Population and Social Security Research 2013, p. 67). But there has been substantial change in attitudes toward whether marriage and childbearing themselves are necessary. In the 1990s, for the 
four attitudinal items that measured the necessity of marrying and having children, the proportion holding a nontraditional position increased by an average of 10 percentage points. And results from the 2010 census show that both men and women are continuing to postpone marriage. The proportion never-married reached 35 percent for women aged 30-34 and 36 percent for men aged 35-39 (ibid., p. 109). The Japanese are clearly picking and choosing where and how family values and behaviors will change.

\section{Acknowledgments}

The analyses reported here were partially supported by a grant from NICHD to the East-West Center (5R01HD042474). Emi Tamaki provided excellent programming and research assistance.

\section{References}

Akabayashi, Hideo. The labor supply of married women and spousal tax deductions in Japan-A structural estimation. Review of Economics of the Household. 2006; 4:349-378.

Aruga, Kizaemon. "Kazoku to ie" (Family and the ie in Japan). Testugaku. 1960; 38:79-110.

Atoh, Makoto. Very low fertility in Japan and value change hypotheses. Review of Population and Social Policy. 2001; 10:1-21.

Brewster, Karin L.; Padavic, Irene. Change in gender-ideology, 1977-1996: The contributions of intracohort change and population turnover. Journal of Marriage and the Family. 2000 May.62:477487.

Brinton, Mary C. Christmas cakes and wedding cakes: The social organization of Japanese women's life course. In: Lebra, Takie Sugiyama, editor. Japanese Social Organization. Honolulu: University of Hawaii Press; 1992. p. 79-107.

Brinton, Mary C., editor. Women's Working Lives in East Asia. Stanford University Press; 2001.

Brinton, Mary C., editor. Lost in Transition: Youth, Work and Instability in Postindustrial Japan. New York: Cambridge University Press; 2011.

Brooks, Clem; Bolzendahl, Catherine. The transformation of US gender role attitudes: Cohort replacement, social-structural change, and ideological learning. Social Science Research. 2004; 33:106-133.

Bumpass, Larry L. What's happening to the family? Interactions between demographic and institutional change. Demography. 1990; 27:483-498. [PubMed: 2249741]

Bumpass, Larry L.; Choe, Minja Kim. Attitudes relating to marriage and family life. In: Tsuya, Noriko O.; Bumpass, Larry L., editors. Marriage, Work, and Family Life in Comparative Perspective: Japan, South Korea, and the United States. Honolulu: University of Hawaii Press; 2004. p. 19-38.

Bumpass, Larry L.; Rindfuss, Ronald R.; Choe, Minja Kim; Tsuya, Noriko O. The institutional context of low fertility: The case of Japan. Asian Population Studies. 2009; 5(3):215-235.

Casterline, John B. Diffusion processes and fertility transition: Introduction. In: Casterline, John B., editor. Diffusion Processes and Fertility Transition. Washington, DC: National Academy Press; 2001. p. 1-38.

Cotter, David; Hermsen, Joan M.; Vanneman, Reeve. The end of the gender revolution? Gender role attitudes from 1977 to 2008. American Journal of Sociology. 2011; 117(1):259-289.

Chang, Mariko Lin. The evolution of sex segregation regimes. American Journal of Sociology. 2000; 105(6):1658-1701.

Cotis, Jean-Philippe. Toward sustainable economic growth in Japan: The new mix of monetary and fiscal policy. paper prepared for a meeting at Policy Research Institute, Japan Ministry of Finance, Tokyo, 26 June; 2003.

Davis, James A. Changeable weather in a cooling climate atop the liberal plateau: Conversion and replacement in forty-two general social survey items 1972-1989. Public Opinion Quarterly. 1992; 56:261-306. 
Duncan, Greg J.; Boisjoly, Johanne; Harris, Kathleen Mullan. Sibling, peer, neighbor, and schoolmate correlations as indicators of the importance of context for adolescent development. Demography. 2001 Aug; 38(3):437-447. [PubMed: 11523270]

Eurostat. Live births outside marriage. 2012. http://europa.eu/geninfo/legal_notices_en.htm. Assessed $12 / 06 / 2012$

Firebaugh, Glenn. Methods for estimating cohort replacement effects. In: Clogg, Clifford C., editor. Sociological Methodology. Oxford: Basil Blackwell; 1989. p. 243-262.

Fortin, Nicole M. Gender role attitudes and the labour-market outcomes of women across OECD countries. Oxford Review of Economic Policy. 2005; 21(3):416-438.

Genda, Yuji. A Nagging Sense of Job Insecurity. Tokyo: International House of Japan; 2005.

Granovetter, Mark. The strength of weak ties. American Journal of Sociology. 1973; 78:1360-1380.

Hirao, Keiko. Mothers as the best teachers: Japanese motherhood and early childhood education. In: Brinton, Mary C., editor. Women's Working Lives in East Asia. Stanford University Press; 2001. p. 180-203.

Igarashi Y. "Hi-seiki-koyō no genjyo to kadai: Wakamono no mondai wo chūshin-to-shite" (Current situations of non-regular employment: Focusing on young persons). Rippou to Chosa. 2009; 288:183-188.

Inglehart, Ronald; Baker, Wayne E. Modernization, cultural change, and the persistence of traditional values. American Sociological Review. 2000 Feb.65:19-51.

Inglehart, Ronald; Norris, Pippa; Welzel, Christian. Gender equality and democracy. Comparative Sociology. 2002; 1:3-4. 321-345.

Kosei-rodo-sho (Japan Ministry of Health, Labour and Welfare). Kaisei Ikuji Kaigo Kyugyo Ho no Aramashi (Outline of the Revised Child and Family Care Leave Law). Tokyo: Kosei-rodo-sho; 2010.

Kosei-rodo-sho (Japan Ministry of Health, Labour and Welfare). Ikuji Kyugyo Kyufu (Provisions Associated with Childcare Leave). Tokyo: Kosei-rodo-sho; 2013a.

Kosei-rodo-sho (Japan Ministry of Health, Labour and Welfare). Koyou Hoken Seido (The National Employment Insurance System). 2013b. http://www.mhlw.go.jp/stf/seisakunitsuite/bunya/ koyou_roudou/koyou/koyouhoken/index.html). Accessed on 5 December 2013

Kosei-rodo-sho (Japan Ministry of Health, Labour and Welfare). Heisei-24-nendo Koyo Kinto Kihon Chosa no Gaikyo (Summary of the 2012 Basic Survey on Equal Employment). Tokyo: Koseirodo-sho; 2013c.

Kosei-rodo-sho (Japan Ministry of Health, Labour and Welfare). Hoikusho Kanren Jokyo Torimatome (Heisei-25-nen 4-gatu 1-nichi) (Summary Report on the Conditions Relating to Childcare Centers in Japan, as of 1 April, 2013. Tokyo: Kosei-rodo-sho; 2013d.

Lee, Kristen Schultz; Tufiş, Paula A.; Alwin, Duane F. Separate spheres or increasing equality? Changing gender beliefs in postwar Japan. Journal of Marriage and Family. 2010 Feb.72:184-201.

Lee, Kristen Schultz; Fujita, Yumiko. Economic recession and the nature and pace of social change in Japan. Social Science Research. 2011; 40:784-795.

Levey, Tania; Catherine, B Silver. Gender and value orientations-What's the difference? The case of Japan and the United States. Sociological Forum. 2006; 21(4):559-691.

Lutz, Wolfgang; Skirbekk, Vegard; Testa, Maria Rita. The low fertility trap hypothesis: Forces that may lead to further postponement and fewer births in Europe. In: Philipov, D.; Liefbroer, AC.; Billari, FC., editors. Vienna Yearbook of Population Research 2006. 2006. p. 167-192.

Manski C. Identification of endogenous social effects: The reflection problem. Review of Economics Studies. 1993; 60:531-542.

Mason, Karen O.; Lu, Y. Attitudes towards women's familial roles: Changes in the United States 1977-1985. Gender and Society. 1988; 2:39-57.

Moffitt, Robert A. Policy interventions, low-level equilibria, and social interactions. In: Durlauf, Steven N.; Young, H Peyton, editors. Social Dynamics. Washington, DC: Brookings Institution; Press: 2001. p. 45-82. 
Montgomery, Mark R.; John, B Casterline. The diffusion of fertility control in Taiwan: Evidence from pooled cross-section and time-series models. Population Studies. 1993; 47:457-479. [PubMed: 11613198]

Morris, Martina. Overview of network survey designs. In: Morris, Martina, editor. Network Epidemiology: A Handbook for Survey Design and Data Collection. London: Oxford University Press; 2004. p. 8-21.

Mouw, Ted. Estimating the causal effect of social capital: A review of recent research. Annual Review of Sociology. 2006; 32:79-102.

Naikakufu (Cabinet Office, the Government of Japan). Shoshika Shakai Taisaku Hakusho: Heisei-24nendo Shoshika no Jokyo oyobi Shoshika heno Taisho Shisaku no Gaikyo (2012 White Paper on Policy Responses to Low Fertility). Tokyo: Naikakufu; 2012.

National Institute of Population and Social Security Research. Latest Demographic Statistics 2013. Tokyo: National Institute of Population and Social Security Research; 2013. (In Japanese.)

Ogawa, Naohiro; Mason, Andrew; Chawla, Amonthep; Matsukura, Rikiya; Tung, An-Chi. Declining fertility and the rising cost of children: What can NTA say about low fertility in Japan and other Asian countries? Asian Population Studies. 2009; 5(3):289-307.

Raymo, James M. Premarital living arrangements and the transition to first marriage in Japan. Journal of Marriage and the Family. 2003; 65:302-315.

Raymo, James M.; Iwasawa, Miho; Bumpass, Larry. Marital dissolution in Japan: Recent trends and differentials. Demographic Research. 2004; 11:395-419.

Raymo, James M.; Iwasawa, Miho; Bumpass, Larry. Recent trends and educational differentials in marital dissolution in Japan. Journal of Population Problems. 2005; 61(3):50-67. (In Japanese.).

Retherford, Robert D.; Ogawa, Naohiro; Matsukura, Rikiya. Late marriage and less marriage in Japan. Population and Development Review. 2001; 27(1):65-102.

Retherford, Robert D.; Ogawa, Naohiro; Sakamoto, Satomi. Values and fertility change in Japan. Population Studies. 1996; 50(1):5-25. [PubMed: 11609136]

Rindfuss, Ronald R.; Choe, Minja Kim; Bumpass, Larry L.; Tsuya, Noriko O. Social networks and family change in Japan. American Sociological Review. 2004; 69(6):838-861.

Roberts, Glenda. Similar outcomes, different paths: The cross-national transfer of gendered regulations of employment. In: Walby, Sylvia; Gottfried, Heidi; Gottschall, Karin; Osawa, Mari, editors. Gendering the Knowledge Economy. New York: Palgrave Macmillan; 2007. p. 140-160.

Shishido, Kuniaki; Iwai, Noriko; Yasuda, Tokio. Designing response categories of agreement scales for cross-national surveys in East Asia: The approach of the Japanese general social surveys. International Journal of Japanese Sociology. 2009; 18:97-111.

Somusho Tokeikyoku (Statistics Bureau, Japan Ministry of Internal Affairs and Communications). Heisei-18-nen shakai seikatsu kihon chosa (The 2006 survey on time use and leisure activities). Tokyo: Somusho; 2006.

Statistics Japan. Statistical Handbook of Japan, Chapter 12. 2012. www.stat.go.jp/english/data/ handbook/c12cont. Accessed 16 August 2012

Taeuber, Irene B. The Population of Japan. Princeton University Press; 1958.

Thornton, Arland; Young-DeMarco, Linda. Four decades of trends in attitudes toward family issues in the United States: The 1960s through the 1990s. Journal of Marriage and Family. 2001 Nov. 63:1009-1037.

Tsuya, Noriko O. Waga-kuni ni okeru Kazoku-keisei Pataan to Youin (Patterns and Covariates of Partnership Formation in Japan. Journal of Population Problems. 2009; 62(1-2):1-19.

Tsuya, Noriko O.; Bumpass, Larry L. Introduction. In: Tsuya, Noriko O.; Bumpass, Larry L., editors. Marriage, Work, and Family Life in Comparative Perspective: Japan, South Korea, and the United States. Honolulu: University of Hawaii Press; 2004. p. 1-18.

Tsuya, Noriko O.; Bumpass, Larry L.; Choe, Minja Kim; Ronald, R Rindfuss. Is the gender division of labour changing in Japan? Asian Population Studies. 2005; 1(1):47-67.

Tsuya, Noriko O.; Bumpass, Larry L.; Choe, Minja Kim; Ronald, R Rindfuss. Employment and household tasks of Japanese couples, 1994-2009. Demographic Research. 2012; 27:705-718. [PubMed: 24031165] 
Tsuya, Noriko O.; Choe, Minja Kim. Investments in children's education, desired fertility, and women's employment. In: Tsuya, Noriko O.; Bumpass, Larry L., editors. Marriage, Work, and Family Life in Comparative Perspective: Japan, South Korea, and the United States. Honolulu: University of Hawaii Press; 2004. p. 76-94.

van Egmond, Marcel; Janeen, Baxter; Sandra, Buchler; Western, Mark. A stalled revolution? Gender role attitudes in Australia, 1986-2005. Journal of Population Research. 201010.1007/ s12546-010-9039-9

Vogel, Ezra F. Japan's New Middle Class: The Salary Man and His Family in a Tokyo Suburb. 2. Berkeley: University of California Press; 1971.

Yamaguchi, Kazuo. Multinomial logit latent-class regression models: An analysis of the predictors of gender role attitudes among Japanese women. American Journal of Sociology. 2000; 105(6):17021740.

Yoshitomi, Masaru. Japan emerges from the shadow of deflation. Japan Echo: An Interactive Journal of Informed Opinion. 2004 Aug.31(4)

Yu, Wei-hsin. Jobs for mothers: Married women's labor force reentry and part-time, temporary employment in Japan. Sociological Forum. 2002; 17:493-523.

$\mathrm{Yu}$, Wei-hsin. Changes in women's postmarital employment in Japan and Taiwan. Demography. 2005; 42(4):693-717. [PubMed: 16463917]

$\mathrm{Yu}$, Wei-hsin. Better off jobless? Scarring effects of contingent employment in Japan. Social Forces. 2012; 90(3):735-768. 

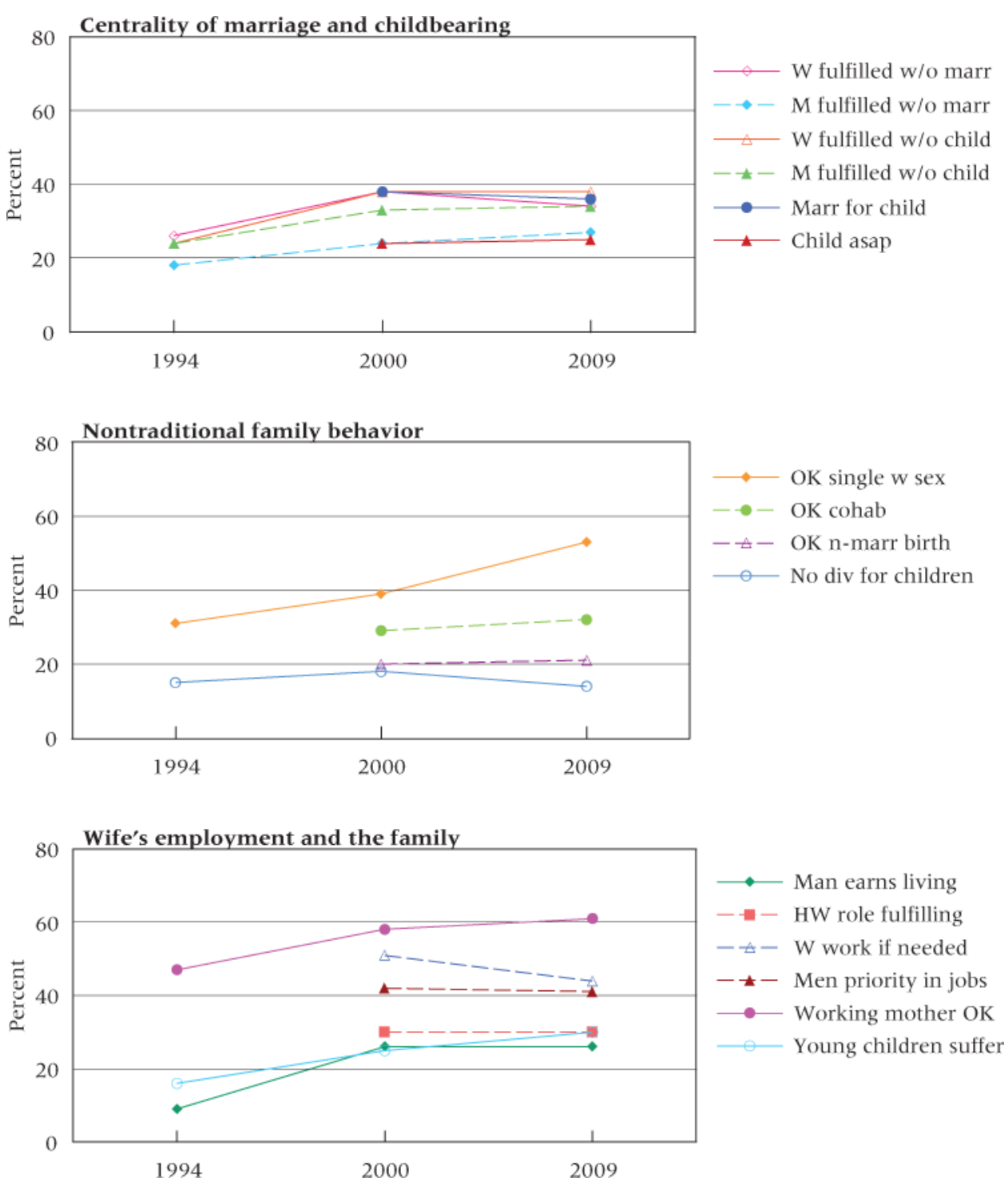

FIGURE 1.

Percent reporting nontraditional attitudes in 1994, 2000, and 2009 

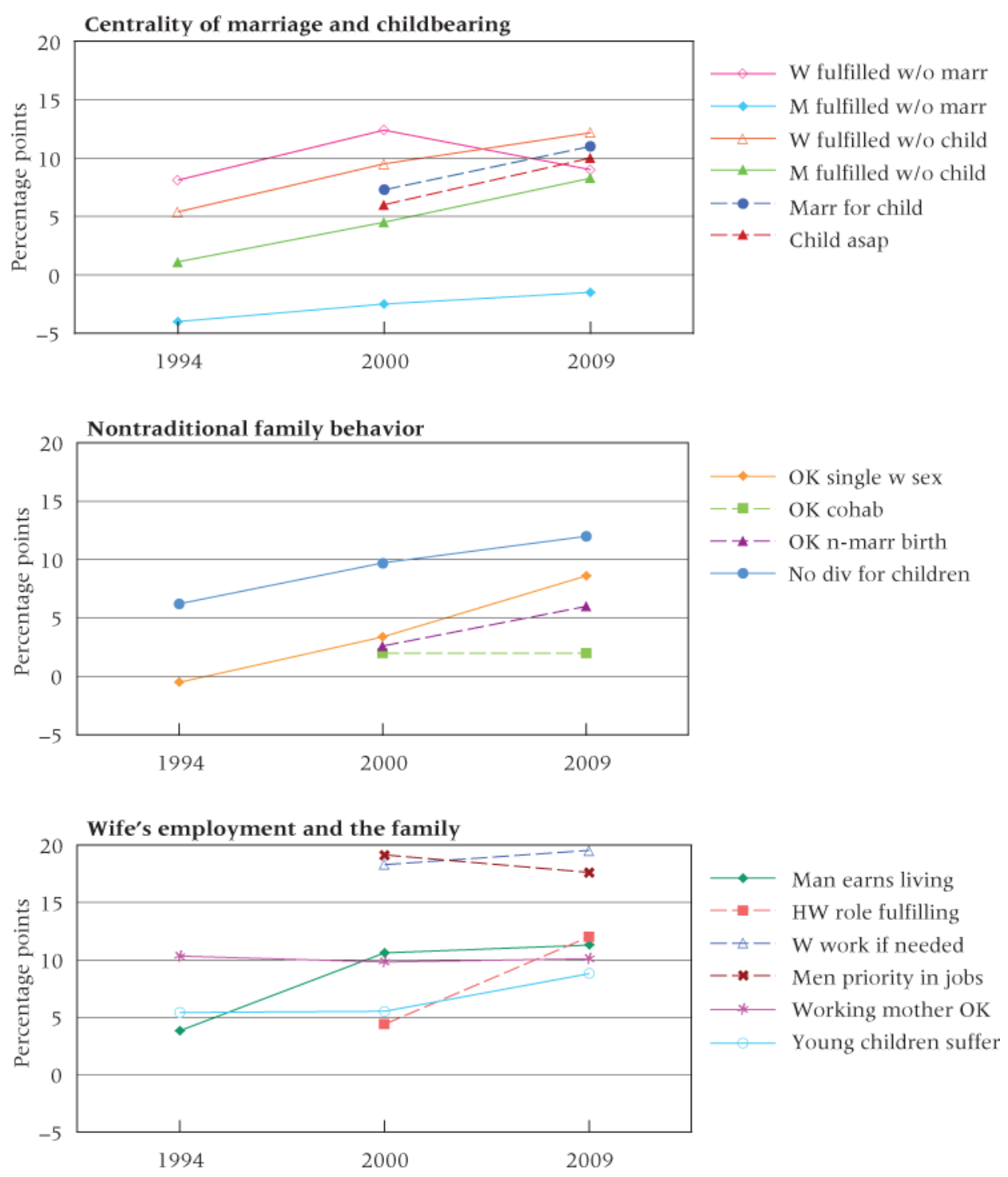

FIGURE 2.

Percentage point differences by sex in nontraditional attitudes in 2009 (percent among women minus percent among men) 
Women work only for extra income

Priority for men when jobs scarce

Woman full life without children

No divorce for the sake of children

Housewife role fulfilling

Better if man earns living

Children main purpose of marriage

Working mother good relationship with children

Children soon after marriage

Woman full life without marriage

Preschool child suffers if mother works

OK unmarried woman sex

Man full life without children

OK nonmarital birth

OK cohabitation

Man full life without marriage

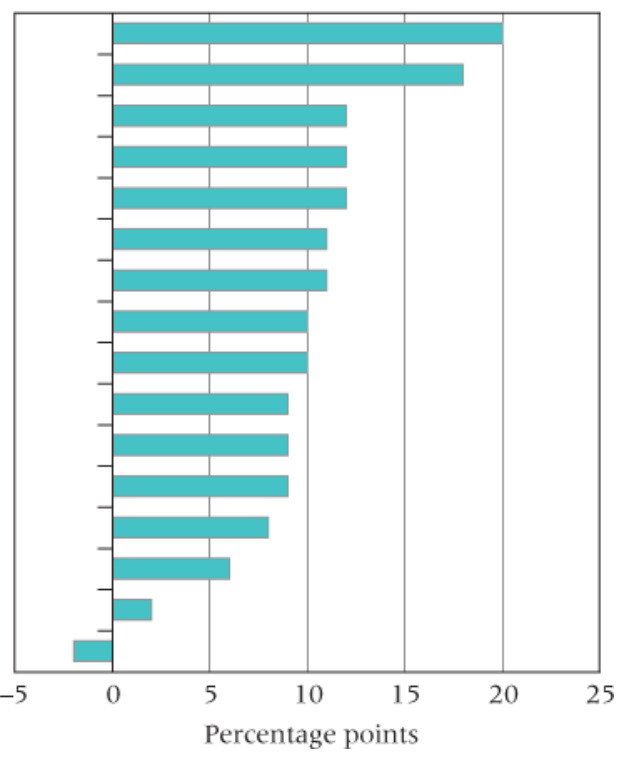

FIGURE 3.

Percentage point differences (females minus males) in the percent reporting nontraditional attitudes 


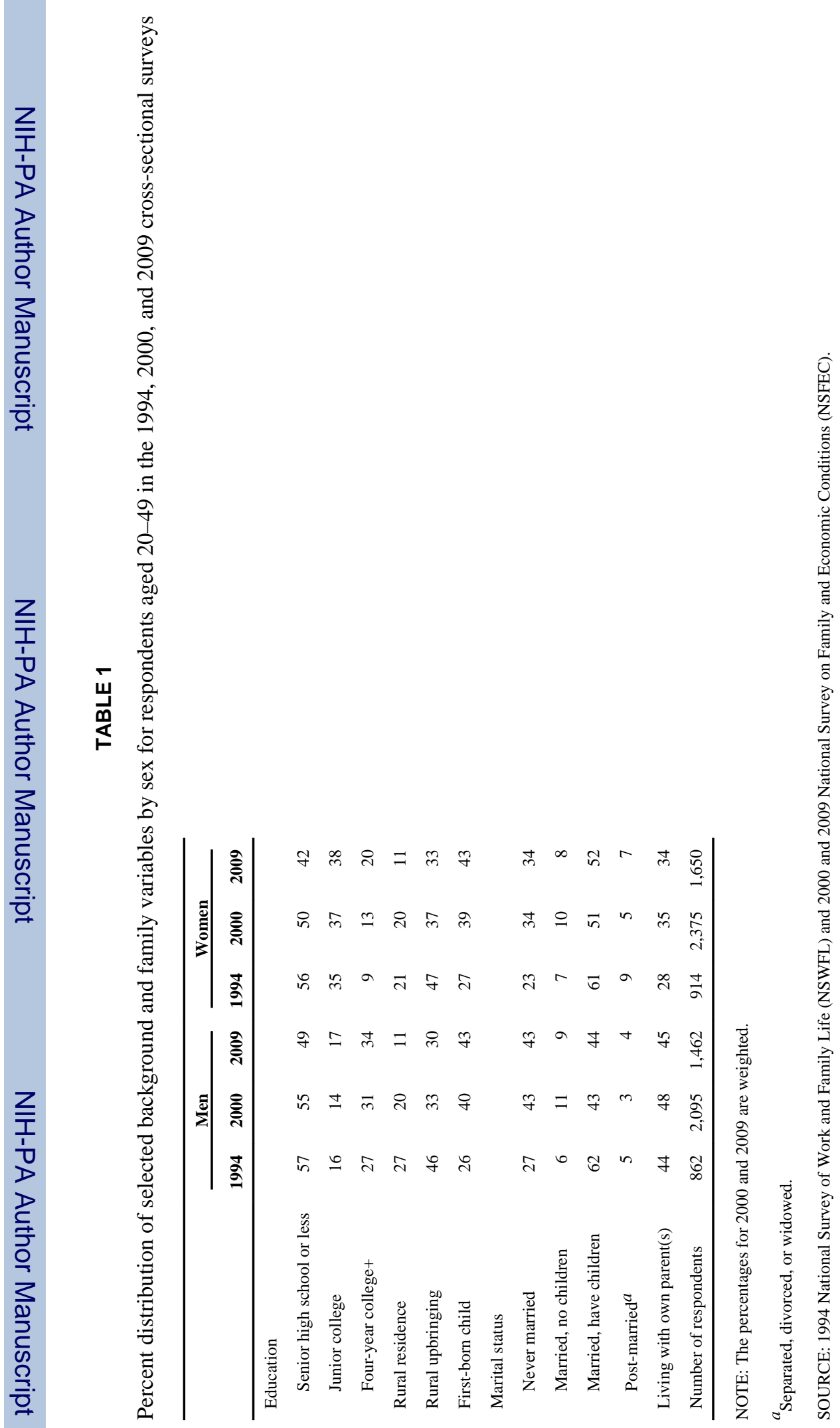

Popul Dev Rev. Author manuscript; available in PMC 2015 June 01. 


\section{TABLE 2}

Attitude questions, responses considered nontraditional, and coverage in three surveys

\begin{tabular}{|c|c|c|c|}
\hline Attitude question & $\begin{array}{l}\text { Attitude is } \\
\text { nontraditional if } \\
\text { the response is }\end{array}$ & Inclusion in surveys & Abbreviation \\
\hline \multicolumn{4}{|l|}{ Centrality of marriage and childbearing } \\
\hline Woman can have a full and satisfying life without marrying. & Agree & All & W fulfilled w/o marr \\
\hline Man can have a full and satisfying life without marrying. & Agree & All & M fulfilled w/o marr \\
\hline Woman can have a full and satisfying life without having children. & Agree & All & W fulfilled w/o child \\
\hline Man can have a full and satisfying life without having children. & Agree & All & M fulfilled w/o child \\
\hline Main purpose of marriage is to have children. & Disagree & 2000,2009 & Marr for child \\
\hline Couple should have their first child as soon as possible after marriage. & Disagree & 2000,2009 & Child asap \\
\hline \multicolumn{4}{|l|}{ Nontraditional family behavior } \\
\hline Acceptable for an unmarried woman to have sex. & Agree & All & OK single w sex \\
\hline $\begin{array}{l}\text { A young man and woman should not live together unless they are } \\
\text { married. }\end{array}$ & Disagree & 2000,2009 & OK cohab \\
\hline Acceptable for a woman to have children without marrying. & Agree & 2000,2009 & OK n-marr birth \\
\hline Parents should stay together (not divorce) for the sake of their children. & Disagree & All & No div for children \\
\hline \multicolumn{4}{|l|}{ Wife's employment and the family } \\
\hline $\begin{array}{l}\text { Much better for everyone if the man earns the main living and the } \\
\text { woman takes care of the home and family. }\end{array}$ & Disagree & All & Man earns living \\
\hline Being a housewife is just as fulfilling as working for pay. & Disagree & 2000,2009 & HW role fulfilling \\
\hline $\begin{array}{l}\text { Wives should work outside home only when the family needs extra } \\
\text { income. }\end{array}$ & Disagree & 2000,2009 & W work if needed \\
\hline When jobs are scarce, men should have priority over women. & Disagree & 2000,2009 & Men priority in jobs \\
\hline $\begin{array}{l}\text { A working mother can establish just as warm and secure a relationship } \\
\text { with her children as a mother who does not work. }\end{array}$ & Agree & All & Working mother OK \\
\hline Preschool children are likely to suffer if their mother works. & Disagree & All & Young children suffer \\
\hline
\end{tabular}




\section{TABLE 3}

Cohorts covered by the three surveys and their ages at each survey

\begin{tabular}{lrrr}
\hline & \multicolumn{3}{c}{ Age in } \\
\cline { 2 - 4 } Birth cohort & $\begin{array}{l}\mathbf{1 9 9 4} \\
(\mathbf{N})\end{array}$ & $\begin{array}{l}\mathbf{2 0 0 0} \\
(\mathbf{N})\end{array}$ & \multicolumn{1}{c}{$\begin{array}{l}\mathbf{2 0 0 9} \\
(\mathbf{N})\end{array}$} \\
\hline $1981-89$ & & & $20-28$ \\
& & & $(890)$ \\
$1975-80$ & & $20-25$ & $29-34$ \\
& & $(976)$ & $(764)$ \\
$1960-74$ & $20-34$ & $26-40$ & $35-49$ \\
& $(765)$ & $(2,589)$ & $(1,458)$ \\
$1951-59$ & $35-43$ & $41-49$ & \\
& $(813)$ & $(905)$ & \\
$1945-50$ & $44-49$ & & \\
& $(398)$ & \\
\hline
\end{tabular}




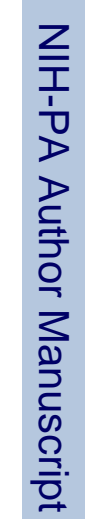

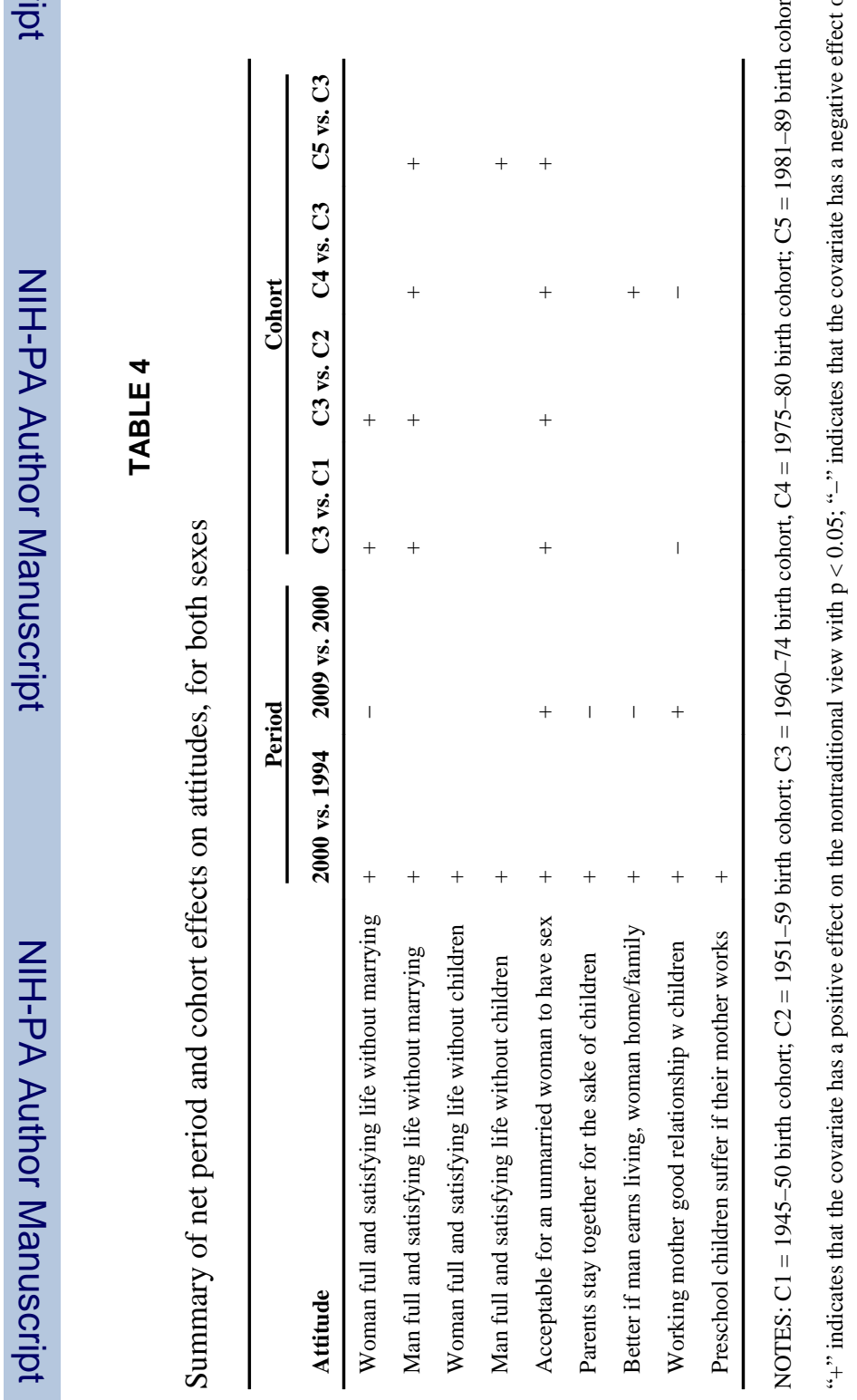

Popul Dev Rev. Author manuscript; available in PMC 2015 June 01. 


\section{TABLE 5}

Sex-specific attitudes with no evidence of endogeneity

\begin{tabular}{lcc}
\hline & Men & Women \\
\hline Woman full and satisfying life without marrying & & \\
Man full and satisfying life without marrying & $\checkmark$ \\
Woman full and satisfying life without children & $\checkmark$ \\
Man full and satisfying life without children & $\checkmark$ \\
Main purpose of marriage is to have children & $\checkmark$ \\
Couple should have their first child soon after marriage & \\
Acceptable for an unmarried woman to have sex & $\checkmark$ \\
Should not live together unless married & $\checkmark$ \\
Acceptable for woman to have children without marrying & $\checkmark$ \\
Parents should not divorce for the sake of children & $\checkmark$ \\
Better if man earns living, woman home/family & $\checkmark$ \\
Housewife as fulfilling as working for pay & \\
Wives work only when family needs extra income & \\
When jobs scarce, men have priority over women & \\
Working mother good relationship w children & \\
Preschool children suffer if their mother works & & $\checkmark$ \\
\hline
\end{tabular}

NOTES:

${ }^{l}$ Endogeneity was tested using Stata procedures “ivregress 2sls" followed by "estat endogenous" and "estat overid." See text for a discussion of endogeneity issues.

2 education, and whether respondent is first-born child.

3 Instrumented variables are 4 categories of marital status and parenthood (never married, currently married without children, currently married with children, post-married), coresidence with parents, and whether the respondent knows anyone who has cohabited.

${ }^{4}$ Instrumental variables are prefecture-level characteristics: percent urban 5 and 10 years ago, ratio of housing units that are rental 7 and 12 years ago, average monthly rent of private rental housing units 5 and 10 years ago, proportions of university graduates who obtained regular employment within one year after graduation for men and women 5 and 10 years ago, proportions of high school graduates going for higher education for men and women 5 and 10 years ago, unemployment rate 10 years ago, ratio of single women aged 20-24 to single men aged 25-29, and ratio of single women aged 25-29 to single men aged 30-34 5 years ago. 


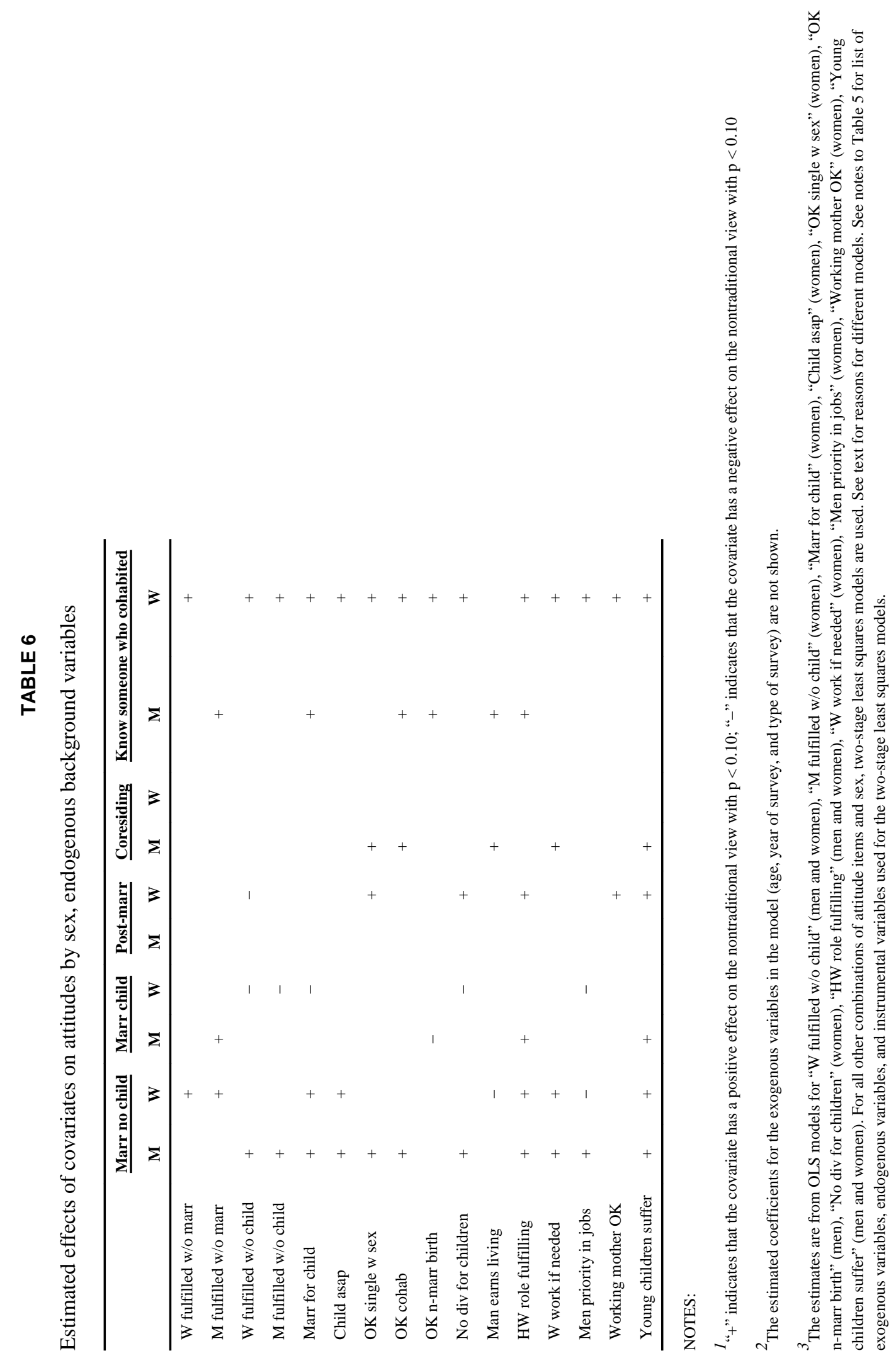

Popul Dev Rev. Author manuscript; available in PMC 2015 June 01. 


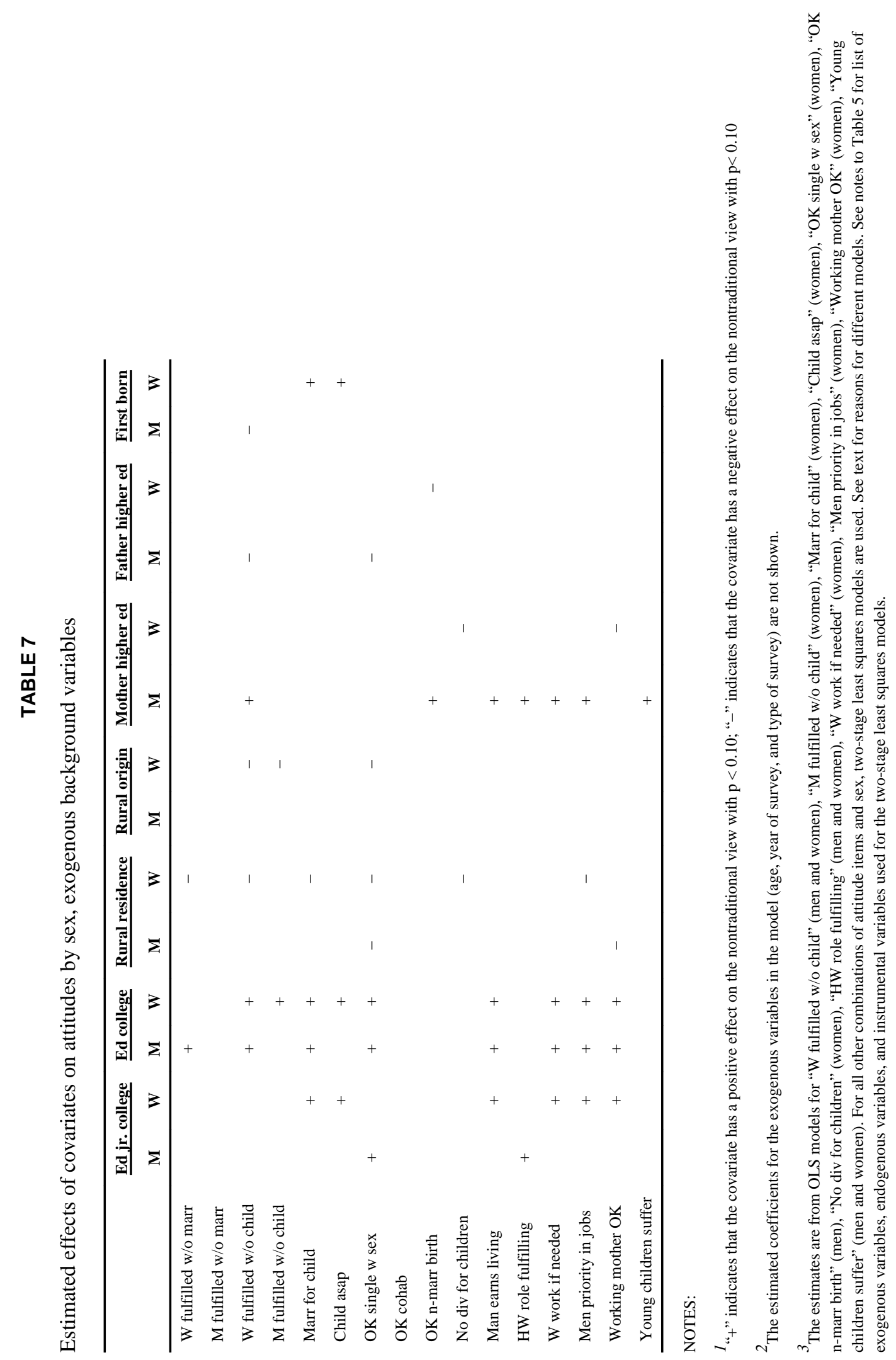

Popul Dev Rev. Author manuscript; available in PMC 2015 June 01. 